\title{
Sistem Informasi Layanan SMS Gateway Bagi Bidan Dalam Program Pemantauan Kesehatan Ibu dan Anak (PWS KIA) di Kabupaten Bantul Provinsi Daerah Istimewa Yogyakarta
}

\author{
Hamzah $^{1}$, Sugeng Winardi ${ }^{2}$ \\ ${ }^{1,2}$ Fakultas Sains dan Teknologi, Universitas Respati Yogyakarta \\ ${ }^{1,2}$ Jl. Laksda Adisucipto Km 6.3 Depok Sleman Yogyakarta \\ ${ }^{1}$ mrhamzahst@gmail.com, ${ }^{2}$ _win_good@yahoo.com
}

\begin{abstract}
Abstrak - Pemantauan wilayah setempat kesehatan ibu dan anak (PWS KIA) merupakan program pemerintah dalam monitoring perkembangan kesehatan ibu dan anak di suatu wilayah. Keberhasilan program PWS KIA tidak terlepas dari peran bidan dalam pengumpulan data dan luas cakupan wilayah sehingga pelaporan baru diperoleh pada periode tertentu sementara informasi yang dibutuhkan bersifat realtime layanan. Pemanfaatan teknologi telekomunikasi khususnya perangkat mobile merupakan teknologi yang banyak digunakan masyarakat dalam berkomunikasi . Pertukaran pesan melalui Sort Message Service (SMS) merupakan media komunikasi yang paling efektif dalam menyampaikan pesan. Perkembangan Teknologi SMS Gateway memungkinkan untuk mengolah data pesan SMS menjadi suatu informasi yang bermanfaat. Berdasarkan uraian diatas, maka adapun tujuan penelitian mengembangkan sistem layanan SMS gateway dalam program PWS KIA dengan metode waterfall dalam pengembangan perangkat lunak. Pengembangan sistem menggunakan bahasa pemrograman PHP, DBMS MySQL dan Gammu SMS Gateway. Hasil penelitian diharapkan dapat memberikan kemudahan bagi bidan untuk melaporkan setiap layanan PWS KIA secara realtime dan diharapkan Dinas Kesehatan Bantul dapat memperoleh data terbaru layanan PWS KIA tanpa harus menunggu dalam periode tertentu.
\end{abstract}

Kata kunci : SMS Gateway, Sort Message Service, PWS KIA

\begin{abstract}
Monitoring local areas of maternal and child health (PWS KIA) is a program of the government in monitoring the development of maternal and child health in the region. The success of PWS MCH program of the role of midwives in routine data collection and reporting of maternal and child health in the health centers. Bantul local government efforts to obtain information PWS KIA often constrained in every region will be coverage of the area so that the new reporting obtained at a certain period while the required information is realtime service. Utilization of telecommunications technology, especially mobile devices is a technology that is widely used in communication society. Exchange messages via the Sort Message Service (SMS) is the most effective communication medium in conveying the message. Technology Developments SMS Gateway allows for data processing SMS messages into a useful information. Based on the description above, as for the purpose of research to develop a system of SMS gateways in the PWS KIA program with waterfall method in software development. System development using PHP, MySQL DBMS and Gammu SMS Gateway. The results are expected to provide convenience for the midwife to report any PWS KIA services in realtime and is expected Bantul Health Office can obtain the latest data PWS KIA services without having to wait for a certain period.
\end{abstract}

Keywords: SMS Gateway, Sort Message Service, PWS KIA

\section{PENDAHULUAN}

Menurut Pedoman Pemantauan Wilayah Setempat Kesehatan Ibu dan Anak yang diterbitkan Dinas Kesehatan (PWS KIA). PWS KIA adalah alat manajemen untuk melakukan pemantauan program Kesehatan Ibu dan Anak (KIA) di suatu wilayah kerja secara terus menerus, agar dapat dilakukan tindak lanjut yang cepat dan tepat.

Pemerintah dalam hal ini Departemen Kesehatan sebenarnya sudah mengembangkan suatu aplikasi khusus untuk Pemantauan Wilayah Setempat Kesehatan Ibu dan Anak (PWS KIA) secara detail dan terus menerus dikembangkan. Namun permasalahan yang ditemukan adalah pemenuhan sarana prasarana teknologi informasi (TIK) disemua layanan kesehatan yang tentunya membutuhkan dana infrastruktur yang cukup mahal. Hal ini belum pelaksanaan pelatihan bagi surveillance aktif/bidan dalam menggunakan aplikasi tersebut. 
Dinas Kesehatan Kabupaten Bantul memiliki beberapa puskesmas disetiap kecamatan. Selama ini dalam pengumpulan data masih dilakukan dengan pendataan secara manual dengan mengisi formulir yang sudah ditentukan atau dengan aplikasi yang sudah dikembangkan oleh Dinas Kesehatan. Namun hal tersebut menjadi kendala bagi daerah-daerah yang masih belum terjangkau infrasturktur jaringan komputer, kurangnya tenaga operator komputer yang trampil IT di puskesmas-puskesmas dan kurangnya penguasaan teknologi informasi bagi bidan di lapangan.

Beberapa penelitian yang sudah dilakukan terkait peninjauan Kesehatan Ibu dan Anak telah merumuskan beberapa kesimpulan terkait infrasturktur jaringan komputer, kurangnya tenaga operator komputer yang trampil IT di puskesmaspuskesmas, dan kurangnya penguasaan teknologi informasi bagi bidan di lapangan.

Yahya[1] menjelaskan bahwa penerapan sistem informasi , implementasi program kartini yang menjadi alat pendukung utama dalam pengolahan data kegiatan PWS KIA , masalah umum yang terjadi adalah pada persoalan interaksi antara pengguna (dalam hal ini bidan) dengan perangkat IT seperti komputer kurang mendukung, tidak mengerti lingkungan dalam komputer dan tidak adanya support dari dinas kesehatan kabupaten dalam membantu masalah-masalah teknis dengan berbagai macam alasan.

Senewe dan Wiryawan[2] menjelaskan dari hasi penelitiannya bahwa sebagian besar para bidan di desa ini merupakan pegawai tidak tetap/bukan PNS. Umumya bidan di desa malas melakukan pencatatan dan pelaporan PWS-KIA karena terlalu banyak pencatatan dan pelaporan yang harus dikerjakan oleh bidan di desa, termasuk menjalankan tugas profesi selaku bidan. Juga para bidan di desa ini dimintakan oleh pimpinan puskesmas untuk membantu tugastugas kebidanan di Puskesmas atau jaga malam di bagian kebidanan puskesmas.

Seiring perkembangan teknologi informasi, perkembangan teknologi telekomunikasi juga khususnya perangkat mobile merupakan perangkat telekomunikasi yang sudah umum di masyarakat, yang selama ini difungsikan sebagai media komunikasi dan memberikan informasi dan jangkauannya sudah hampir di seluruh wilayah indonesia.

Penggunaan perangkat mobile sudah menjadi hal yang umum bagi masyarakat, khususnya penggunaaan fitur SMS Message sebagai sarana berkomunikasi dan memberikan informasi yang sangat sederhan dan mudah digunakan. Perkembangan teknologi perangkat lunak dalam hal ini layanan SMS secara terpusat (SMS Gateway) juga sudah semakin berkembang. Beberapa penelitian terkait pemanfaat layanan SMS Message sudah banyak dikembangkan dan diteliti untuk dapat menunjang layanan-layanan publik di berbagai bidang.

Dessyanto, dkk[3] telah berhasil merancang dan membangun aplikasi SMS notifikasi kesehatan balita, memiliki kemampuan antara lain: satu nomor handphone pelanggan dapat digunakan untuk mendaftarkan banyak nama balita selama nama balita tidak ada yang sama, mengirimkan informasi secara periodik kepada pelanggan setiap bulan sesuai dengan tanggal lahir balita, pengirimkan informasi jadwal imunisasi dilakukan secara manual oleh admin.

Novianti dan Fauziah[4] Membangun Sistem Informasi Sekolah Dasar Berbasis SMS yang dirancang dengan menggunakan UML dan mempunyai fungsi sebagai pemberi informasi absensi dan kegiatan siswa di sekolah kepada orang tua siswa agar lebih mudah dan efisien melalui SMS. Orang tua tidak perlu repot lagi datang ke sekolah hanya untuk mengetahui kegiatan dan absensi siswa.

Rahardja, dkk[5] mengembangkan aplikasi mobile-banking yang dapat membantu nasabah bank memperoleh berbagai layanan mulai dari registrasi, mentransfer saldo, mengecek saldo, melihat informasi suku bunga, melihat valuta asing, dan pembayaran tagihan listrik/telepon dengan menggunakan handphone dengan mudah dan praktis; (2)UML dapat membantu mengatasi perancangan pembuatan sebuah aplikasi yang akan dibuatl; (3) Pembuatan aplikasi mobile banking bersifat user friendly sehingga memudahkan nasabah dalam pengoperasiannya.

Dari uraian permasalahan yang dihadapi Dinas Kesehatan untuk memperoleh secara real time kegiatan layanan kesehatan ibu dan anak yang telah dilakukan surveillance aktif/bidan lapangan dan hasil kajian penelitian terdahulu untuk mengkaji implementasi program kartini dan beberapa pengembangan layanan berbasis mobile, maka perlu adanya pengembangan sistem yang dapat membantu surveillance aktif/bidan lapangan untuk mengirimkan hasil kegiatan layanan PWS-KIA melalui pesan SMS.

Tujuan penelitian ini adalah merancang bangun sistem informasi layanan SMS gateway bagi tenaga surveilence aktif/bidan dalam pemantauan wilayah setempat kesehatan ibu dan anak (PWS-KIA).

\section{METODOLOGI PENELITIAN}

\section{A. Metode Pengumpulan Data}

Merupakan kegiatan di awal untuk memperoleh data-data dan informasi terkait proses pengolahan dokumen yang saat ini berjalan dengan menggunakan metode pengumpulan Data. Adapun metode pengumpulan data tersebut adalah sebagai berikut:

\section{Studi Literatur}


Berupa pencarian sumber-sumber bacaan yang dapat menunjang penelitian yang diambil. Yaitu :Hasil-hasil penelitian terdahulu yang memiliki kesamaan dalam penelitian.

a. Penelitian tentang pemantauan wilayah setempat kesehatan ibu dan anak.

b. Penelitian tentang SMS Gateway.

2. Sumber Data-data

a. Sumber Data Primer

Adalah data yang diperoleh langsung dari Instansi baik melalui pengamatan maupun pencatatan terhadap obyek penelitian.

Jenis datanya antara lain :

1) Proses bisnis yang sedang berjalan.

2) Dokumen Laporan.

b. Sumber Data Sekunder

Adalah data yang diambil secara tidak langsung dari objek penelitian. Data ini diperoleh dari buku-buku, dokumentasi, dan literatur-literatur berupa :

1) Panduan Pemantauan Wilayah Setempat PWS-KIA.

2) Dokumen Laporan.

c. Pengumpulan data-data

Berupa pengumpulan data penunjang yang dapat membantu perancangan sistem. Sehingga penulis melakukan pengumpulan data-data dengan cara observasi yaitu pengumpulan data melalui pengamatan dan pencatatan terhadap gejala atau peristiwa yang diselidiki pada obyek penelitian secara langsung. Antara lain : Proses pencatatan kunjungan ibu hamil oleh surveilence aktif.

\section{B. Metode Pengembangan Perangkat Lunak}

1. Analisa

a. Identifikasi Awal, melakukan pengumpulan data terkait proses bisnis yang saat ini berjalan, data dan informasi yang dibutuhkan. b. Merumuskan Kelayakan Sistem, berdasarkan identifikasi awal yang sudah dilakukan berdasarkan infrastruktur, perangkat keras, perangkat lunak dan sumber daya manusia.

c. Merumuskan Kebutuhan Sistem, berdasarkan identifikasi awal, berdasarkan data dan informasi yang dibutuhkan.

2. Rancangan

a. Arsitektur Sistem, memberikan gambaran secara umum proses operasional sistem.

b. Model Proses, memberikan gambaran proses aliran data dan informasi.

c. Model Data, memberikan gambaran rancangan data secara logic dan pisik pada media penyimpan.

d. Rancangan Antar Muka

1) Rancangan Masukan, rancangan tampilan proses dari input data.

2) Rancangan Keluaran, rancangan tampilan informasi dari hasil proses input data.

3. Coding, merupakan proses pembuatan aplikasi berdasarkan hasil analisa dan rancangan.

\section{HASIL DAN PEMBAHASAN}

\section{A. Analisa Sistem}

Analisa sistem merupakan tahapan yang harus dilakukan sebelum melakukan rancangan dengan metode pengumpulan data. Adapun analisa yang dilakukan adalah analisa proses bisnis, identifikasi ketersedian data, identifikasi ketersedian informasi, identifikasi exiting system dan identifikasi sumber informasi.

\section{B. Analisa Proses Bisnis}

Analisa proses bisnis merupakan analisa untuk mengetahui proses/prosedur yang terjadi di lapangan terhadap kegiatan pengolahan data menjadi informasi dalam kegiatan pemantauan wilayah setempat kesehatan ibu dan anak. Seperti pada Gambar 1.

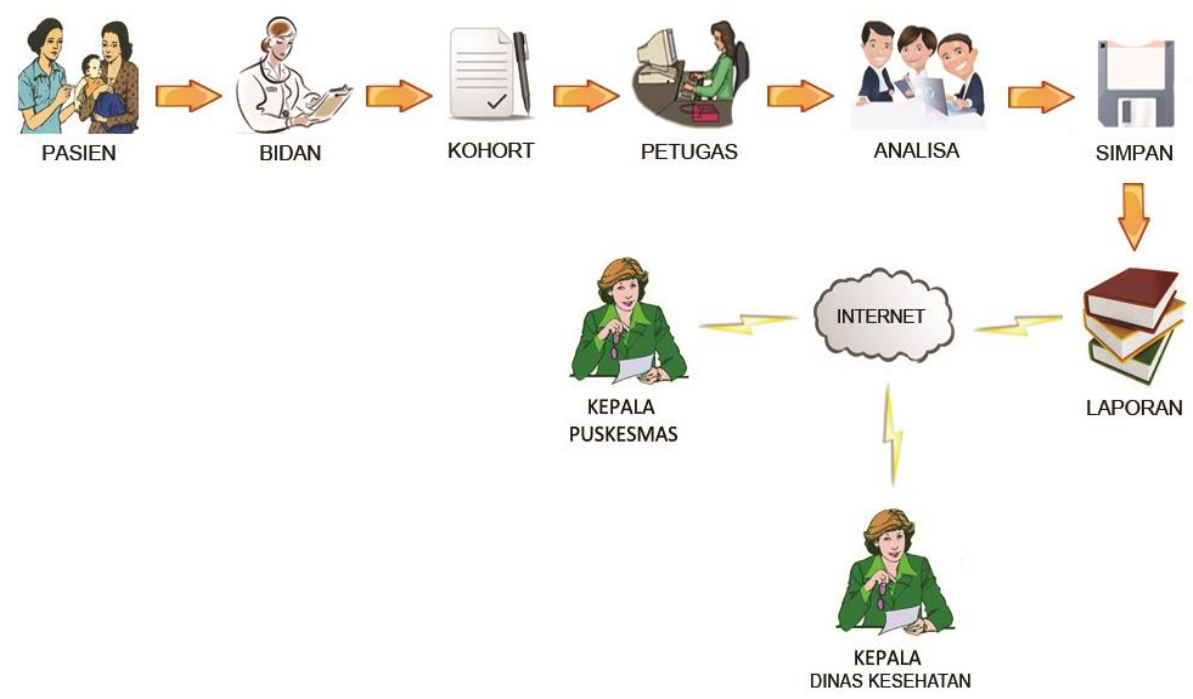

Gambar 1. Proses Pengolahan Data PWS-KIA 


\section{Identifikasi Ketersediaan Data}

Wilayah Kabupaten Bantul memiliki 17 kecamatan, 75 Desa, dan 933 Dusun seperti daftar berikut ini.

Tabel 1. Jumlah Desa, Dusun dan Luas Kecamatan di Kabupaten Bantul

\begin{tabular}{clcc}
\hline No & Kecamatan & $\begin{array}{c}\text { Jumlah } \\
\text { Desa }\end{array}$ & $\begin{array}{c}\text { Jumlah } \\
\text { Dusun }\end{array}$ \\
\hline 1 & Srandakan & 2 & 43 \\
2 & Sanden & 4 & 62 \\
3 & Kretek & 5 & 52 \\
4 & Pundong & 3 & 49 \\
5 & Bambanglipuro & 3 & 45 \\
6 & Pandak & 4 & 49 \\
7 & Pajangan & 3 & 55 \\
8 & Bantul & 5 & 50 \\
9 & Jetis & 4 & 64 \\
10 & Imogiri & 8 & 72 \\
11 & Dlingo & 6 & 58 \\
12 & Banguntapan & 8 & 57 \\
13 & Pleret & 5 & 47 \\
14 & Piyungan & 3 & 60 \\
15 & Sewon & 4 & 63 \\
16 & Kasihan & Sedayu & 53 \\
17 & Jumlah & 54 \\
\hline & & 45 & \\
\hline & 53 & 53 \\
\hline
\end{tabular}

Di dalam wilayah kabupaten bantul sendiri terdapat 27 pukesmas yang tersebar di beberapa kecamatan. Adapun daftar puskesmas yang terdapat di wilayah Kabupaten Bantul adalah sebagai berikut.

1. Puskesmas Srandakan

2. Puskesmas Sanden

3. Puskesmas Kretek

4. Puskesmas Pundong

5. Puskesmas Bambanglipuro

6. Puskesmas Pandak I

7. Puskesmas Pandak II

8. Puskesmas Bantul I

9. Puskesmas Bantul II

10. Puskesmas Jetis I

11. Puskesmas Jetis II

12. Puskesmas Imogiri I

13. Puskesmas Imogiri II

14. Puskesmas Dlingo I

15. Puskesmas Dlingo II

16. Puskesmas Pleret

17. Puskesmas Piyungan

18. Puskesmas Banguntapan I

19. Puskesmas Banguntapan II

20. Puskesmas Banguntapan III

21. Puskesmas Sewon I

22. Puskesmas Sewon II

23. Puskesmas Kasihan I
24. Puskesmas Kasihan II

25. Puskesmas Pajangan

26. Puskesmas Sedayu I

27. Puskesmas Sedayu II

\section{Identifikasi Ketersediaan Informasi}

Ketersediaan informasi pada kegiatan Pemantauan Wilayah Setempat Kesehatan Ibu dan Anak (PWSKIA) dijelaskan pada tabel 2.

\begin{tabular}{ll}
\multicolumn{2}{c}{ Tabel 2. Ketersediaan Data } \\
\hline \multicolumn{1}{c}{ Format Data } & \multicolumn{1}{c}{ Rincian } \\
\hline Dokumen (hardcopy) & Ada \\
Database/Tabel & Tidak ada \\
Dokumen (Softcopy) & Ada \\
\hline
\end{tabular}

\section{E. Kebutuhan Sistem}

1. Kebutuhan Fungsional

Analisis kebutuhan fungsional dilakukan untuk mengetahui keunggulan yang ada dalam sistem yang baru. Adapun kebutuhan fungsional dari sistem yang baru adalah sebagai berikut.

a. Sistem Informasi berbasis Web dengan perangkat lunak pengembangan adalah PHP.

b. Pengelolaan database (DBMS) menggunakan MySQL.

c. SMS Gateway menggunakan Gammu SMS Gateway.

d. Aplikasi nantinya merupakan aplikasi layanan SMS yang ditujukan bagi bidan dan petugas di puskesmas dalam memberikan data hasil kunjungan pemantauan wilayah setempat kesehatan ibu dan anak melalui perangkat handphone berupa SMS Message.

e. Aplikasi dapat memberikan informasi-informasi terkait program KIA.

\section{Kebutuhan Non Fungsional}

Analisis kebutuhan non-fungsional dilakukan untuk mendukung kinerja ssstem. Adapun kebutuhan non-fungsional dari sistem yang baru adalah sebagi berikut :

a. Analisa Kebutuhan Perangkat Keras (Hardware).

Adapun kebutuhan perangkat keras yang dibutuhkan untuk mengoperasikan sistem yang baru adalah sebagai berikut :

1) 1 Unit Central Processing Unit (CPU).

2) Monitor.

3) Mouse.

4) Keybord.

5) Modem.

6) Handphone.

b. Analisa kebutuhan Perangkat Lunak (Software). Dalam membangun sistem ini membutuhkan beberapa kebutuhan perangkat lunak, diantaranya:

1) Webserver : Xampp 1.7.4

2) Gammu versi 1.25 .0 
3) $D B M S: M y S Q L$

4) Web Browser

5) YII Framework 1.1.13

c. Analisis Sumber Daya Manusia (brainware)

Analisis kebutuhan SDM merupakan tahap untuk menganalisa orang-orang yang terlibat dalam sistem. Adapun kebutuhan SDM yang terlibat dalam pengembangan sistem adalah SDM yang mampu mengoperasikan komputer. Adapun SDM tersebut antara lain sebagai berikut.

1) Bidan

Bidan adalah orang yang bertugas untuk menginputkan data hasil kunjungan pemeriksaan ibu hamil di temapt layanan. Data tersebut dikirim ke sistem PWS-KIA yang berada di puskesmas menggunakan SMS.

2) Petugas Puskesmas

Petugas puskesmas adalah orang yang ditunjuk oleh puskesmas untuk mengelola sistem sms gateway. Petugas puskesmas akan menerima data

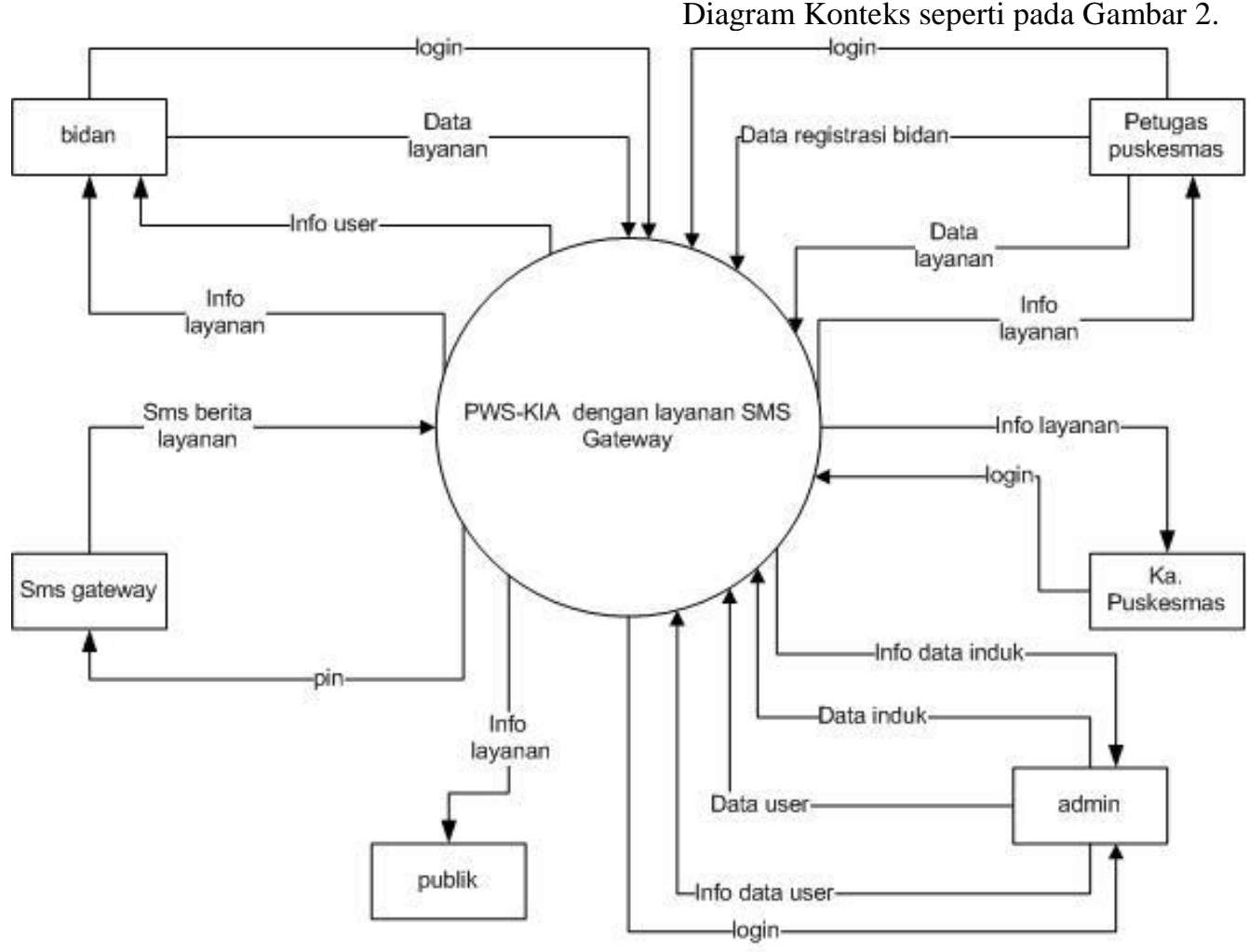

Gambar 2. Diagram Konteks

Keterangan Gambar 2.

a. Bidan adalah petugas kesehatan atau bidan yang bertugas melayani masyarakat khusunya pelayanan pemeriksaan ibu dan anak di Puskesmas.

b. Petugas puskesmas adalah tenaga administrasi di Puskesmas yang bertugas melakukan rekapitulasi pendataan layanan terkait PWS-KIA. yang dikirim oleh bidan, data tersebut akan diolah oleh sistem dan menghasilkan sebuah laporan.

\section{3) Kepala Puskesmas}

Kepala puskesmas akan menerima laporan dari petugas puskesmas. Bisa juga melihat informasi dan laporan melalui web.

4) Masyarakat

\section{F. Perancangan Sistem}

Perancangan sistem merupakan tahapan yang dilakukan setelah melakukan tahapan analisa. Perancangan yang dilakukan meliputi perancangan model proses, model data, arsitektur sistem, perancangan input dan perancangan output.

\section{Model Proses}

Model proses digunakan untuk menggambarkan kerja sistem yang akan dikembangkan dalam hal ini proses aliran data menjadi informasi dan entitas yang terlibat/berinteraksi dengan sistem. Perancangan sistem secara garis besar dapat digambarkan ke dalam Diagram Konteks seperti pada Gambar 2.

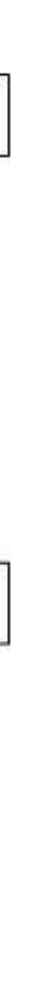

c. SMS Gateway merupakan perangkat keras modem dan sistem service yang menangani layanan SMS yaitu pengiriman pesan singkat dan menerima pesan singkat yang diproses melalui PC.

d. Adalah petugas IT di Puskesmas yang bertugas dalam mengolah data digital. Dalam sistem bertugas melakukan pengelolaan user dan data induk. 
e. Ka. Puskesmas merupakan pimpinan atau penganggung jawab layanan di Puskesmas.

f. Publik merupakan masyarakat umum.

\section{Model Data}

a. Entity Relationship Diagram (ERD) Entity Relationship Diagram (ERD) merupakan diagram yang digunakan untuk menggambarkan relasi antar tabel dalam basisdata yang nantinya akan digunakan dalam aplikasi layanan PWS-KIA. Adapun diagram relasi tabel seperti pada gambar .

Keterangan Gambar.

- Kecamatan $=\{\underline{\text { id }}, \underline{\text { kode_kecamatan, }}$ nama_kecamatan $\}$

- Desa $=\{$ id, kode_kecamatan, $\underline{\text { kode desa }}$, nama_desa\}
- Tempatlayanan $=\{\underline{\text { idd }}, \underline{\text { kode } \text { kecamatan, }}$, kode_desa, kode_tmpt_layanan, nama_tmptlayanan\}

- Bidan $=\{\underline{\text { id }}$, kode kecamatan, kode_desa, kode tmpt layanan, pin bidan, nama_bidan, telp_bidan, alamat\}

- Jenis_layanan $=\left\{\underline{\text { id}}, \underline{\text { kode } j s \_l a y a n a n}\right.$, nama_layanan\}

- Tindakan_layanan $=\{\underline{\mathrm{id}}$, kode js layanan, kode_tindakan, nama_tindakan $\}$

- $\mathrm{Ibu}=\{\underline{\mathrm{id}}, \underline{\text { kode kecamatan }}, \underline{\text { kode desa }}$, kode_tmpt_layanan, regibu, namaibu, namasuami

- Balita = $\{\underline{\mathrm{id}}, \underline{\text { kode kecamatan, }}$ kode desa, kode_tmpt_layanan, umur, namaibu, namasuami\}

- Berita_layanan $=\{\underline{\mathrm{id}}, \underline{\text { kode kecamatan, }}$ kode desa, kode tmpt layanan, pin bidan, kode_js_layanan, kode_tindakan, tgl_tindakan \}.

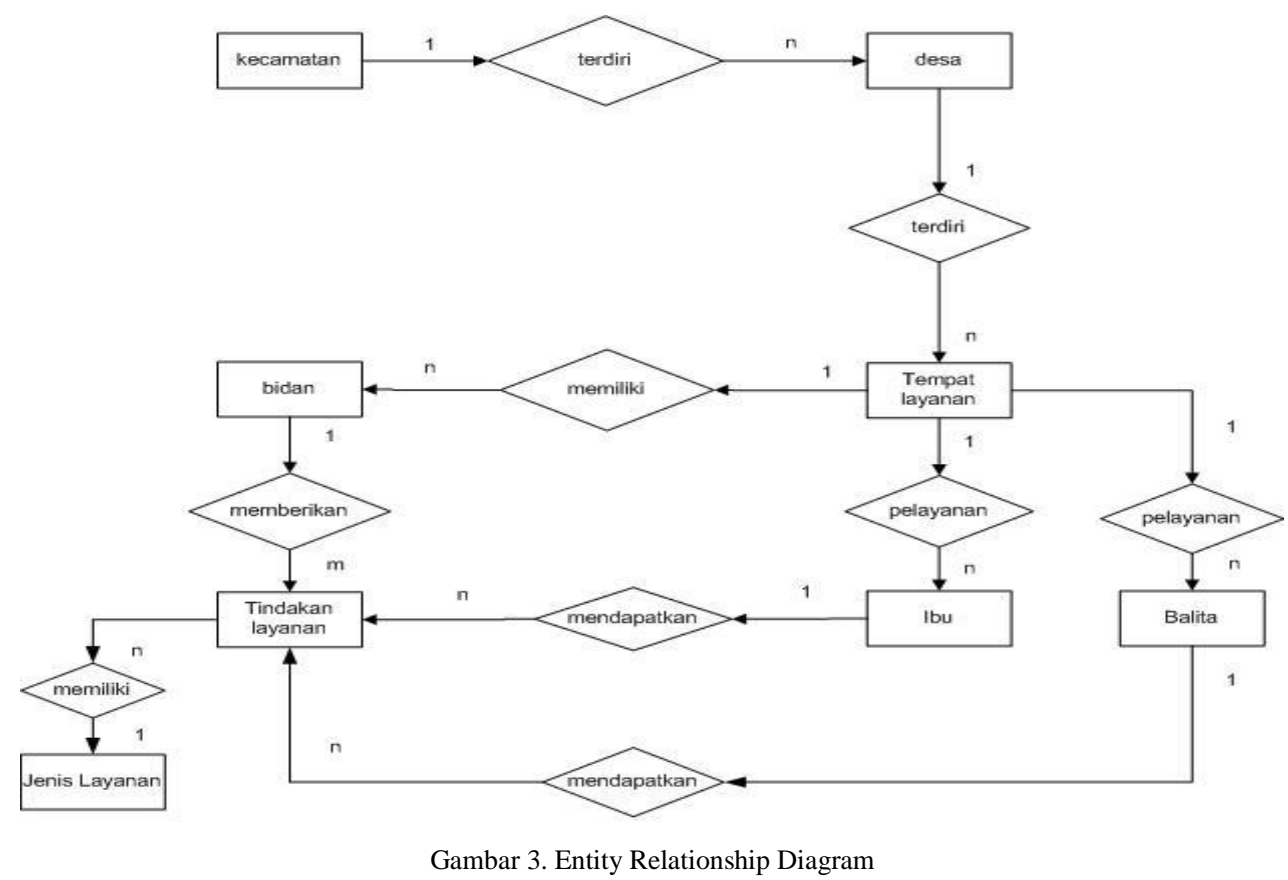

\section{b. Struktur Tabel}

Struktur tabel merupakan rincian lengkap terkait tabel yang digunakan untuk menyimpan data yang terdiri dari rincian nama field, tipe field, ukuran field. Adapun beberapa tabel yang nantinya digunakan dalam basisdata Aplikasi Layanan PWS-KIA seperti pada rincian.

1) Tabel untuk menyimpan data bidan

Tabel ini digunakan untuk menyimpan biodata bidan beserta PIN bidan sebagai acuan bidan dalam pengiriman SMS, seperti pada Tabel 3.
Tabel 3. Tabel Bidan

\begin{tabular}{lll}
\hline Nama field & Tipe & Pjg \\
\hline Id_bidan & Int & 10 \\
Nama_bidan & Varchar & 50 \\
U_name & Varchar & 30 \\
Pin & Varchar & 6 \\
Id_puskesmas & Int & 10 \\
\hline
\end{tabular}

2) Tabel untuk menyimpan data desa

Tabel ini digunakan untuk menyimpan data desa yang terdapat di wilayah kabupaten bantul. Seperti pada Tabel 4. 


\begin{tabular}{llc}
\multicolumn{3}{c}{ Tabel 4. Tabel Desa } \\
\hline Nama field & Tipe & pjg \\
\hline Id_desa & Int & 4 \\
Nama_desa & Varchar & 30 \\
Id_kecamatan & Int & 2 \\
\hline
\end{tabular}

3) Tabel untuk menyimpan data kecamatan

Tabel ini digunakan untuk menyimpan data kecamatan yang terdapat di wilayah Kabupaten Bantul. Seperti pada Tabel 5.

\begin{tabular}{ccc}
\multicolumn{3}{c}{ Tabel 5.Tabel Kecamatan } \\
\hline Nama field & Tipe & Pjg \\
\hline Id_kecamatan & Int & 2 \\
Nama_kecamatan & Varchar & 30 \\
\hline
\end{tabular}

4) Tabel untuk menyimpan data tempat layanan, seperti pada Tabel 6.

Tabel 6. Tabel Puskesmas

\begin{tabular}{llc}
\hline \multicolumn{1}{c}{ Nama field } & Tipe & pjg \\
\hline Id_puskesmas & Int & 10 \\
Nama_puskesmas & Varchar & 30 \\
Alamat_puskesmas & Varchar & 75 \\
Id_desa & Int & 4 \\
\hline
\end{tabular}

5) Tabel untuk menyimpan registrasi data ibu, seperti pada Tabel 7.

Tabel 7. Tabel Ibu

\begin{tabular}{llc}
\hline \multicolumn{1}{c}{ Nama field } & \multicolumn{1}{c}{ Tipe } & pjg \\
\hline No_registrasi & Int & 20 \\
Nama_ibu & Varchar & 50 \\
Nama_bapak & Varchar & 50 \\
Umur & Int & 4 \\
KIA & Enum & - \\
K1 & Enum & - \\
K2 & Enum & - \\
K3 & Enum & - \\
K4 & Enum & - \\
Id_bidan & Int & 10 \\
Tg1_input & Date & - \\
\hline
\end{tabular}

6) Tabel untuk menyimpan data group. Struktur tabel seperti pada Tabel 8 .
Tabel 8. Tabel Group

\begin{tabular}{llc}
\hline \multicolumn{1}{c}{ Nama field } & Tipe & pjg \\
\hline Id_group & Int & 11 \\
Nama_group & Varchar & 50 \\
Jenis_group & Varchar & 20 \\
\hline
\end{tabular}

7) Tabel untuk menyimpan data petugas

Tabel ini digunakan sebagai tempat menyimpan data petugas. Adapun struktur tabel seperti pada Tabel 9.

Tabel 9. Tabel Petugas

\begin{tabular}{llc}
\hline \multicolumn{1}{c}{ Nama field } & \multicolumn{1}{c}{ Tipe } & Pjg \\
\hline Id_petugas & Int & 11 \\
Nama_petugas & Varchar & 75 \\
Alamat_petugas & Varchar & 75 \\
Id_group & Int & 4 \\
U_name & Varcar & 30 \\
U_pass & Varcar & 30 \\
\hline
\end{tabular}

\section{Perancangan Antarmuka (Interface)}

Perancangan antarmuka merupakan perancangan yang berkaitan dengan sistem PWS-KIA. Berikut ini adalah rancangan antarmuka data sistem PWS-KIA.

1. Rancangan antarmuka login.

2. Rancangan antarmuka update kecamatan.

3. Rancangan antarmuka update desa.

4. Rancangan antarmuka update puskesmas.

5. Rancangan antarmuka update user group.

6. Rancangan antarmuka update data petugas.

7. Rancangan antarmuka data hasil pemeriksaan.

8. Rancangan antarmuka informasi daftar kecamatan.

9. Rancangan antarmuka informasi daftar desa.

10. Rancangan antarmuka daftar user group.

11. Rancangan antarmuka informasi daftar petugas.

12. Rancangan antarmuka informasi daftar bidan.

13. Rancangan antarmuka data kunjungan pemeriksaan.

14. Rancangan halaman laporan data kunjungan pemeriksaan.

15. Rancangan antarmuka laporan rekap data kunjungan pemeriksaan.

\section{Arsitektur Sistem}

Aplikasi nantinya dikembangkan dengan menggunakan layanan berita singkat (SMS) oleh bidan lapangan ketika melakukan pemeriksaaan/layanan kepada masyarakat yang langsung diterima aplikasi di server dan pada saat yang sama dapat diakses user berkepentingan (Ka. Puskemas dan Dinas Kesehatan Kabupaten) untuk memantau laporan PWS-KIA. 


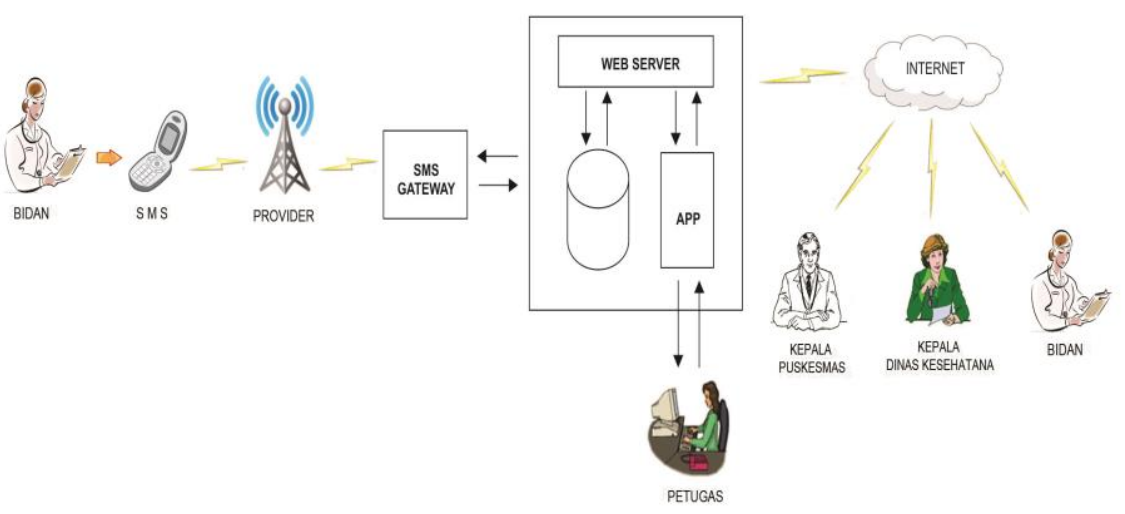

Gambar 4. Arsitektur Sistem

\section{Format pengiriman $S M S$}

Dalam setiap melakukan layanan serang bidang lapangan mengirimkan berita layanan ke aplikasi menggunakan perangkat mobile dengan menggunakan aturan pengiriman berita berupa format layanan SMS ( Short Message Service) yang kemudian pesan singkat berita layanan tersebut diterima aplikasi dengan format layanan sms sebagai berikut.

\section{PIN\#KODEPUSKESMAS\#KODE LAYANAN \#IPELAYANAN\#JML\#KETERANGAN}

\begin{tabular}{|l|l|l|l|l|l|}
\hline $\mathbf{9 ( 5 )}$ & $\mathbf{9 ( 5 )}$ & $\mathbf{X}(2)$ & $\mathbf{X}(2)$ & 99 & $\mathbf{X}(\mathbf{2 0})$ \\
\hline
\end{tabular}

Keterangan dari kode SMS.

PIN

KODE

PUSKESMAS

KODE

LAYANAN

JML

KETERANGAN
: Merupakan kode pin dari petugas bidan lapangan yang melakukan layanan pada masyarakat Jumlah digit $=5$ Digit Format digit $=$ Angka Merupakan kode puskesmas.

Jumlah digit $=5$ digit

Format digit $=$ karakter

Merupakan kode layanan yang ditangani oleh seorang bidan lapangan. Jumlah digit $=$ Format digit $=$ Karakter

TIPE LAYANAN : Merupakan tipe layanan dari layanan yang dilakukan oleh bidan. Jumlah digit $=$ Format digit $=$ karakter

Merupakan jumlah layanan yang ditangani oeh seorang bidan lapangan.

Jumlah digit $=2$ digit

Format digit $=$ Angka

Merupakan Keterangan yang diperlukan dalam layanan oleh seorang bidan lapangan

Jumlah digit $=20$ digit

Format digit $=$ Karakter

6. Implementasi Sistem

Tahap implementasi merupakan tahap akhir dari sebuah perancangan aplikasi. Tahap ini akan menggambarkan dan menjelaskan langkah-langkah dalam operasional aplikasi.

a. Persyaratan implementasi sistem

Dalam Implementasi aplikasi dibutuhkan persyaratan (Hardware dan Software). Hardware yang dibutuhkan dalam penerapan aplikasi adalah PC dan Modem-GSM didukung dengan perangkat lunak XAMPP sebagai web server dan gammu sebagai SMS service pada PC. Perangkat Handphone digunakan sebagai perangkat yang digunakan untuk mengirimkan pesan singkat layanan. Adapun tampilan aplikasi dalam web server seperti pada gambar 5 .

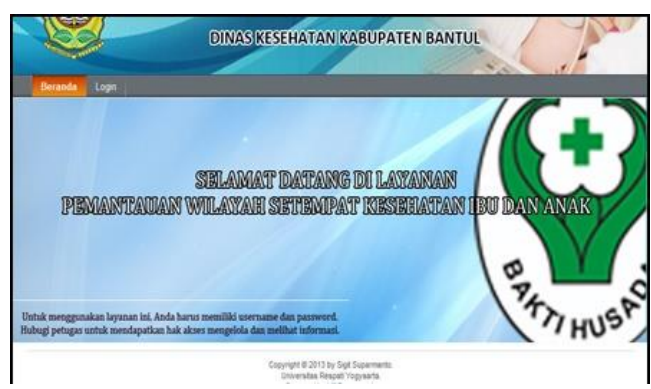

Gambar 5. Tampilan halaman utama aplikasi

Dalam implementasi sistem digunakan juga perangkat mobile sebagai alat uji fungsionalitas sistem dalam pengiriman pesan/berita layanan kesehatan oleh seorang bidan dil apangan. Dalam pengujian melalui perangkat mobile seorang bidan mengirimkan pesan singkat layanan dengan format yang sudah ditentukan dengan respon balik dari sistem ke perangkat mobile, seperti tampilan. 


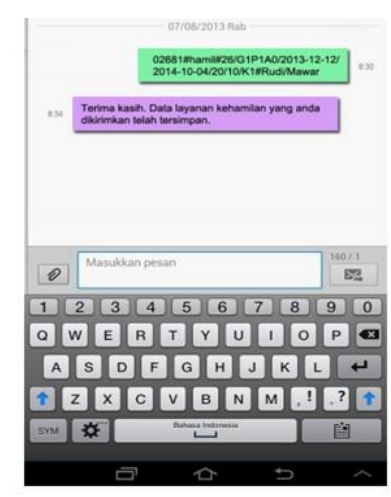

Gambar 6. Tampilan halaman utama aplikasi

Sebagai verifikasi penerimaan pesan, aplikasi juga dikembangkan dengan layanan respon balik secara otomatis pada pengirim pesan. Respon balik secara otomatis yang diberikan pada layanan SMS adalah respon balik jika layanan tidak sesuai format atau kesalahan dalam menuliskan PIN seperti pada gambar 7 dan gambar 8 .

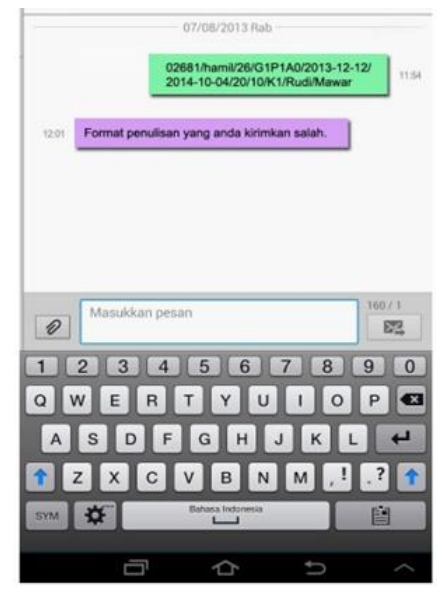

Gambar 7. Respon balik Jika pengiriman tidak sesuai format pengiriman

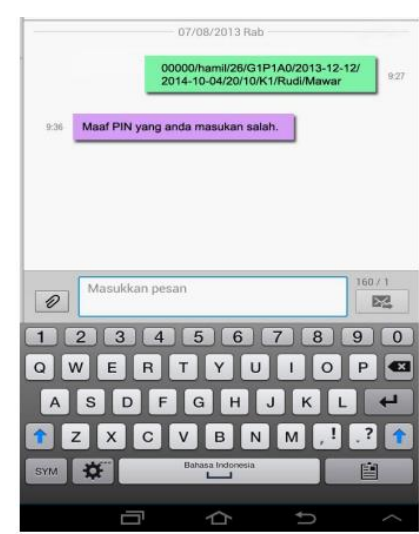

Gambar 8. Respon balik jika kesalahan dalam mengisikan PIN

\section{PENUTUP}

\section{A. Kesimpulan}

Dari Hasil pelaksanaan kegiatan penelitian diperoleh beberapa kemajuan dalam kegiatan penelitian yang dapat disimpulkan sebagai berikut.

1. Pada tahap analisa, terdapat beberapa layanan dalam program PWS-KIA, K1, K4, Persalinan yang ditolong oleh tenaga kesehatan, ibu nifas yang dilayani 3 kali (KF 3) oleh tenaga kesehatan, neonatus yang mendapatkan pelayanan kesehatan pada umur $6-48$ jam, neonatus yang mendapatkan pelayanan kesehatan lengkap (KN lengkap), ibu hamil, bersalin dan nifas dengan faktor risiko /komplikasi yang dideteksi oleh masyarakat, kasus komplikasi obstetri yang ditangani, neonatus dengan komplikasi yang ditangani, bayi 29 hari -12 bulan yang mendapatkan pelayanan kesehatan sedikitnya 4 kali, anak balita (12 - 59 bulan) yang mendapatkan pelayanan kesehatan sedikitnya 8 kali, anak balita sakit yang mendapatkan pelayanan kesehatan sesuai standar, peserta $\mathrm{KB}$ aktif ; Kecamatan dengan jumlah kecamatan yaitu: 17 Kecamatan; Puskesmas: 27 Puskesmas.

2. Pada tahap desain/perancangan, telah dirancang desain model proses dengan menggunakan Model Diagram Arus Data (DAD), model data dengan rancangan konseptual (ERD) dan physical design (Database), model rancangan arsitektur sistem, HIPO dan rancangan antar muka sistem.

\section{B. Saran}

Adapun masukan /saran yang dapat disampaikan dalam tindak lanjut penelitian adalah sebagai berikut:

1. Untuk penelitian selanjutnya perlu adanya uji coba penggunaan SMS Gateway terhadap beberapa provider yang berbeda untuk menguji layanan SMS yang kompetitif.

2. Sejalan dengan perkembangan teknologi telekomunikasi dalam hal ini smartphone, untuk penelitian selanjutnya dapat dikembangkan aplikasi client server dengan pemanfaatan mobile.

\section{DAFTAR PUSTAKA}

[1] Yahya.N, 27 Maret 2010, Bahaya Kegagalan Sistem Informasi,

(http://ppwskia.wordpress.com/category/seputarppws-kia/), diakses Januari 2013

[2] Senewe.F.P, Wiryawan.y. , 2011, Pencatatan dan Pelaporan Sistem Pemantauan Wilayah Setempat Kesehatan Ibu dan Anak oleh Bidan di Desa di Puskesmas Sepatan Kabupaten Tanggerang , Jurnal Ekologi Kesehatan Vol. 10 No 3, September 2011 : $156-167$

[3] Dessyanto B. P., Kaswidjanti W, Sari N.I, 2008, Aplikasi SMS Notifikasi Kesehatan Balita, Seminar Nasional Informatika 2008 (semnasIF 2008) ISSN: 1979-2328 UPN "Veteran" Yogyakarta, 24 Mei 2008 
Sistem Informasi Layanan SMS Gateway Bagi Bidan Dalam Program Pemantauan Kesehatan Ibu dan Anak (PWS KIA) di Kabupaten Bantul Provinsi Daerah Istimewa Yogyakarta

[4] Novianti A., Fauzijah.A, 2009, Sistem Informasi Sekolah Dasar Berbasis SMS, Seminar Nasional Aplikasi Teknologi Informasi 2009 (SNATI 2009) ISSN:1907-5022, Yogyakarta, 20 Juni 2009
[5] Rahardja Y., Presstiliano J., Astuti NP, 2008, Analisis dan Perancangan Mobile-Banking dengan Menggunakan UML, Jurnal Teknologi Informasi, Aiti, Vol. 5. No. 2, Agustus 2008: 101-200 